Artigos

Volume $10-2020 \mid$ n. 2

\title{
A Expansão e o Financiamento da Pós-Graduação no Brasil e a Meta 14 do Plano Nacional de Educação
}

\author{
Caio Eduardo Jardim \\ Universidade de Brasília (UnB), Brasília/DF - Brasil
}

\section{Resumo}

Este trabalho tem como objetivo investigar o cumprimento da meta 14 do Plano Nacional de Educação (PNE) e das estratégias 14.1 e 14.12, especialmente quanto ao financiamento da pós-graduação no Brasil, através da concessão de bolsas a estudantes pelas duas principais agências de fomento: a CAPES e o CNPq. Para isso, é feita a análise de dados oficiais obtidos nas plataformas GEOCAPES, Painel de Investimentos CNPq, SIGA BRASIL, e também nos sites do MCTIC, CAPES, CNPq e IBGE. São apresentadas as metas a serem investigadas, bem como as análises e resultados da pesquisa proposta. As conclusões referentes à pesquisa apontam as dificuldades para o cumprimento do PNE em relação à meta e estratégias investigadas, a necessidade de expandir o financiamento da pós-graduação no Brasil, sobretudo em relação ao orçamento das agências de fomento, e a importância da concessão de bolsas de estudo a pós-graduandos para a elevação da taxa de titulação e o consequente cumprimento da meta 14.

Palavras-chave: Financiamento da Educação. Plano Nacional de Educação. PósGraduação. CAPES. CNPq.

\section{The Expansion and Funding of Postgraduate Education in Brazil and the Goal 14 of the National Education Plan}

\begin{abstract}
This study aims to investigate the compliance of the goal 14 of the National Plan of Education (PNE) and of the strategies 14.1 and 14.12, especially regarding the funding of post-graduate programs in Brazil, through the granting of scholarships to students by the country's two major agencies: CAPES and CNPq. For such, it was analyzed official data obtained from the GEOCAPES, CNPq Investment Panel, SIGA BRASIL platforms, as well as MCTIC, CAPES, CNPq and IBGE websites. The goals to be investigated are presented, as well as the analysis and results of the proposed research. The conclusions of the research points to the difficulties in complying the investigated PNE goals and strategies, the need to expand postgraduate funding in Brazil, especially in relation to the budget of the development agencies, and the relevance of granting scholarships for postgraduate students to increase the titling rate and the resulting achievement of goal 14.
\end{abstract}

Keywords: Education Funding. National Education Plan. Postgraduate Studies. CAPES. CNPq. 
A Expansão e o Financiamento da Pós-Graduação no Brasil e a Meta 14 do Plano Nacional de Educação

\section{Introdução}

O Plano Nacional de Educação (PNE), aprovado em 25 de julho de 2014, e com vigência para o decênio 2014-2024, tornou-se o documento orientador de grande parte dos debates educacionais e das lutas por políticas públicas educacionais. Além disso, apesar das diversas contradições existentes em seu texto, no interior de suas metas e estratégias, o PNE é tido como um paradigma mínimo daquilo em que se precisa avançar em educação e daquilo em que não se pode retroceder.

Em suas 20 metas e em suas respectivas estratégias, o Plano Nacional de Educação abrange a educação em todos os seus níveis, etapas e modalidades, apresentando metas desde a Educação Infantil até o nível de pós-graduação, abordando também outros temas educacionais como gestão democrática, valorização do profissional da Educação, além de tratar de diversas modalidades de ensino como a Educação de Jovens e Adultos (EJA) e a Educação Especial.

Desde sua aprovação em 2014 até o início de 2018, já próximo de completar quatro anos de sua vigência, muitos estudos e pesquisas foram realizados, buscando avaliar o cumprimento das metas, bem como o monitoramento do PNE. Apesar disso, poucos deles são dedicados ao monitoramento do cumprimento e da situação de implementação da meta 14 e de suas estratégias. Essa meta é a principal meta do PNE no que diz respeito diretamente ao ensino de pós-graduação no Brasil, com foco no aumento do número de estudantes titulados em mestrado e doutorado. A meta contém 15 estratégias voltadas para o desenvolvimento e expansão da pós-graduação no Brasil e do número de pós-graduados.

Este trabalho irá debruçar-se justamente sobre a meta 14 do PNE, buscando, a partir da análise de dados oficiais disponíveis, compreender a situação do seu cumprimento, bem como suas perspectivas de efetivação, tendo como principal preocupação a questão do financiamento público para o desenvolvimento da pós-graduação no Brasil.

Além disso, serão analisadas as estratégias 14.1 e 14.12. A primeira diz respeito diretamente à questão de recursos destinados ao financiamento da pós-graduação stricto sensu por meio das agências oficiais de fomento. A segunda prevê uma meta quantitativa de 4 doutores por 1.000 habitantes a ser alcançada no final do decênio.

O estudo adota como recorte de investigação a oferta de bolsas para estudantes de pós-graduação, como um mecanismo de expandir a matrícula e ao mesmo tempo gerar condições para que o estudante matriculado conclua seus estudos e pesquisas, e torne-se, então, titulado. Dessa forma, os recursos para essa finalidade tornam-se cruciais para a concessão dessas bolsas, bem como os recursos destinados às agências oficiais de fomento responsáveis por ofertá-las.

A pesquisa, portanto, tem como objetivos investigar a relação entre o número de matriculados na pós-graduação no Brasil, o número de bolsas oferecidas pelas principais agências de fomento do Governo Federal e os recursos destinados para tal finalidade; e, consequentemente, investigar como o financiamento e a trajetória de bolsas para pósgraduação no Brasil se relacionam à meta 14 do PNE e às estratégias selecionadas.

Toma-se como objeto de análise as duas principais agências nacionais de fomento à pós-graduação, responsáveis por grande parte da oferta de bolsas no País, a Coordenação de Aperfeiçoamento de Pessoal de Nível Superior (CAPES) e o Conselho Nacional de 
A Expansão e o Financiamento da Pós-Graduação no Brasil e a Meta 14 do Plano Nacional de Educação

Desenvolvimento Científico e Tecnológico (CNPq). A análise se dará a partir dos dados do ano de 2004 até o ano de 2016, recorte que se justifica por ser o período em que há os dados quantitativos disponíveis relativos ao objeto desta pesquisa.

Coloca-se, então, a seguinte pergunta de pesquisa a ser respondida e que irá orientar este trabalho: como o financiamento da CAPES e do CNPq influenciou o crescimento do número de matriculados/titulados na pós-graduação por meio da oferta de bolsas, a partir de $2004 ?$

Para alcançar os objetivos pretendidos será feita a análise de dados oficiais disponibilizados pela CAPES, principalmente através da plataforma GEOCAPES, pelo CNPq, pela plataforma Painel de Investimento CNPq e pelo Ministério da Ciência, Tecnologia, Inovações e Comunicações. Além disso, contou-se com a análise de dados orçamentários disponíveis na plataforma Siga Brasil e nos portais das agências de fomento CAPES e CNPq. Todos os dados são de domínio público e de acesso aberto nos sítios eletrônicos das instituições mencionadas.

A pesquisa justifica-se a partir da ausência de trabalhos que se debrucem sobre o cumprimento da meta 14 e suas estratégias, partindo da perspectiva do financiamento da pósgraduação e sua relação com a oferta de bolsas de estudos pelas agências oficiais de fomento.

O trabalho será dividido em duas seções, além desta introdução e da conclusão. $\mathrm{Na}$ primeira seção será discutido e apresentado brevemente o Plano Nacional de Educação, sobretudo em relação às suas metas para a educação superior e para a pós-graduação, principalmente a meta 14 e suas estratégias. Além disso, será apresentado um panorama sobre o financiamento da pós-graduação no Brasil, com ênfase nas duas agências mencionadas.

A segunda seção será dedicada à apresentação e análise dos dados coletados por esta pesquisa, à luz da meta 14 do PNE e das estratégias selecionadas, com o foco na oferta de bolsas pela CAPES e pelo CNPq. Buscaremos, então, identificar as possibilidades e perspectivas de cumprimento da Meta 14 e das estratégias 14.1 e 14.12.

Por fim, o trabalho encerra-se com as considerações finais resultantes da pesquisa realizada, apontando as conclusões extraídas e os desafios postos para o desenvolvimento e expansão da pós-graduação no Brasil.

\section{I - O Plano Nacional de Educação e a Pós-Graduação no Brasil}

A Constituição Federal de 1988 em seu artigo 214 estabelece a criação, na forma de lei, de um plano nacional de educação, e elenca seus principais objetivos. É no texto constitucional, portanto, que está a base formal para a instituição do Plano Nacional de Educação, bem como do estabelecimento de suas metas e estratégias.

Apesar da previsão constitucional, o primeiro PNE existente, com vigência entre 2001 a 2010, não provocou grande impacto na elaboração das políticas educacionais e não assumiu o caráter de referencial e paradigma para o futuro da educação brasileira (DOURADO, 2016). Um dos principais fatores para isso consiste no fato de que o PNE 2001-2010 não previa fontes de financiamento para as metas e estratégias elencadas no plano, devido ao veto do 
A Expansão e o Financiamento da Pós-Graduação no Brasil e a Meta 14 do Plano Nacional de Educação

presidente Fernando Henrique Cardoso aos dispositivos que apontavam fontes de recursos e financiamento para tal (CHAVES; AMARAL, 2014).

Já em 2010, quando o Poder Executivo, no governo de Luiz Inácio Lula da Silva, envia ao Congresso Nacional o projeto do novo Plano Nacional de Educação, há uma nova correlação de forças políticas e um novo entendimento a respeito das políticas sociais e da educação. Além disso, havia também um novo elemento nessa correlação, a Emenda Constitucional $n^{\circ} 59$, de 2009, que determinou que o plano deveria conter entre seus dispositivos uma "meta de aplicação de recursos públicos em educação como proporção do produto interno bruto" (BRASIL, 1988).

Soma-se a isso um grande movimento por parte da sociedade civil, do campo educacional, dos movimentos pela educação, de professores e estudantes, que foi fundamental na consolidação do novo PNE. Movimento este que se consubstanciou na Conferência Nacional de Educação - CONAE 2010, cujo documento final apontou elementos centrais para o novo PNE, como a questão da gestão democrática e o valor de $10 \%$ do PIB, como meta de recursos a serem aplicados na Educação.

O PNE torna-se, então, o principal documento legal de planejamento e orientação da Educação para o período dos dez anos que seguirão a sua aprovação. Tendo como objetivo consolidar-se como uma política de Estado para a Educação (DOURADO, 2016), o PNE apresentou diretrizes, metas e estratégias a serem cumpridas e alcançadas no período de sua vigência.

Dentre as 20 metas contidas no PNE estão abrangidos os diversos níveis e modalidades de ensino, além de metas voltadas para garantir a gestão democrática da educação, a valorização de seus profissionais e o estabelecimento de recursos mínimos a serem investidos, equivalentes a 10\% do Produto Interno Bruto até o ano de 2024.

Das 20 metas, três delas tratam diretamente da educação superior, são elas as metas 12,13 e 14 . A meta 12 estipula taxas de matrículas a serem alcançadas, direcionando uma parte das novas matrículas a serem criadas para o segmento público, conforme prevê o texto legal:

Meta 12: elevar a taxa bruta de matrícula na educação superior para $50 \%$ (cinquenta por cento) e a taxa líquida para 33\% (trinta e três por cento) da população de 18 (dezoito) a 24 (vinte e quatro) anos, assegurada a qualidade da oferta e expansão para, pelo menos, 40\% (quarenta por cento) das novas matrículas, no segmento público (BRASIL, 2014).

Como é possível observar, a meta, além da preocupação em expandir o número de matrículas, reflete a tensão entre os interesses da educação privada e empresarial e a posição daqueles que defendem um ensino público e gratuito em estabelecimentos públicos. Além de estipular um mínimo menor que a metade das novas matrículas na meta, suas estratégias também revelam a intenção de apropriação do fundo público em benefício do Ensino Superior privado, como evidenciam as estratégias 12.6 e 12.20 .

A meta 13 centra seus objetivos na qualificação do corpo docente da educação superior, de forma a estipular um percentual mínimo de mestres e doutores atuantes no quadro docente: 
A Expansão e o Financiamento da Pós-Graduação no Brasil e a Meta 14 do Plano Nacional de Educação

Meta 13: elevar a qualidade da educação superior e ampliar a proporção de mestres e doutores do corpo docente em efetivo exercício no conjunto do sistema de educação superior para $75 \%$ (setenta e cinco por cento), sendo, do total, no mínimo, 35\% (trinta e cinco por cento) doutores (BRASIL, 2014).

A meta, com o intuito de elevar o número de mestres e doutores nos quadros docentes do sistema de educação superior, deve contar para isso com o desenvolvimento da pósgraduação no País, de forma a permitir a titulação de novos mestres e doutores. Nesse sentido, é necessário tanto ampliar o número de mestres e doutores titulados, como também elevar a qualidade do ensino de pós-graduação, a partir de condições concretas e materiais para o desenvolvimento acadêmico, como estruturas e recursos para pesquisas, laboratórios, bolsas e novos investimentos.

A meta 14 refere-se à expansão da pós-graduação no Brasil, prevendo "[...] elevar gradualmente o número de matrículas na pós-graduação stricto sensu, de modo a atingir a titulação anual de 60.000 (sessenta mil) mestres e 25.000 (vinte e cinco mil) doutores" (BRASIL, 2014).

A meta estipula um crescimento para o número de matrículas na pós-graduação sem relacioná-lo a um percentual ou número relativo à oferta. Porém, a meta determina um número absoluto de titulações anuais a ser atingido para mestrado e doutorado, o que demandaria tanto um aumento do número de vagas e matrículas nos cursos de pós-graduação, quanto condições objetivas e materiais para que o estudante matriculado possa chegar ao final ser titulado. Para isso, a oferta de bolsas para os estudantes é um elemento fundamental, responsável tanto por dar condições mínimas para que possam se dedicar ao curso e aos trabalhos acadêmicos, quanto por permitir que adquiram os materiais necessários para suas pesquisas, estudos e atividades.

A partir disso, pressupõe-se que a concessão de bolsas para estudantes, na forma de auxílio financeiro, esteja relacionada, juntamente ao aumento de matrículas, a uma elevação do número de estudantes titulados mestres e doutores. É justamente essa relação que se busca investigar na seção posterior, levando em consideração que para que hajam bolsas ofertadas são necessários recursos públicos, e no Brasil os recursos direcionados para essa finalidade concentram-se majoritariamente nas duas principais agências oficiais de fomento, a CAPES e o CNPq.

Com efeito, selecionou-se como estratégia a ser analisada neste trabalho a estratégia 14.1, que objetiva "expandir o financiamento da pós-graduação stricto sensu por meio das agências oficiais de fomento" (BRASIL, 2014). Sendo a primeira das estratégias elencadas para a meta 14, esta aponta qual deve ser a principal fonte de financiamento da expansão necessária para o cumprimento da meta e de suas estratégias. Apesar de não serem as únicas fontes de recursos para a pós-graduação, a CAPES e o CNPq assumem um papel decisivo nesse cenário:

[...] Segundo dados nacionais a maior estrutura de financiamento no Brasil para as atividades de pós-graduação advém dos recursos públicos federais, na figura da Coordenação de Aperfeiçoamento de Pessoal de nível Superior (CAPES) e do CNPq e, estaduais, por meio das FAP's (Fundações de Amparo à Pesquisa), na promoção direta do financiamento de pesquisas por via de editais. De outro lado, o financiamento da pósgraduação se realiza pelo Ministério da Educação (MEC), mediante o pagamento do 
A Expansão e o Financiamento da Pós-Graduação no Brasil e a Meta 14 do Plano Nacional de Educação

salário de professores com dedicação exclusiva, doutores e com tempo integral para se dedicarem às pesquisas (KATO; FERREIRA, 2016, p. 686).

Apesar de, a nível federal, as duas agências terem papel de protagonistas e maior capacidade orçamentária, é importante ressaltar o papel das FAP's como promotoras do desenvolvimento da pós-graduação no nível estadual. Diante do conjunto das fontes de financiamento da pós-graduação no Brasil, percebe-se que a maioria dos recursos destinados ao desenvolvimento e à manutenção da pós-graduação são provenientes do fundo público, sobretudo, do orçamento da União, que direciona os recursos para as agências federais de fomento.

Chama a atenção que, na meta 14, há a disputa de recursos públicos pelos setores privados empresariais de educação superior, como pode-se verificar pela estratégia 14.3, que prevê "expandir o financiamento estudantil por meio do Fies à pós-graduação stricto sensu" (BRASIL, 2014). Entretanto, até dezembro de 2017, segundo informações obtidas do Ministério da Educação (MEC), não haviam sido destinados recursos para tal finalidade.

Outra estratégia, que também será objeto de investigação deste estudo, é a meta 14.12, que prevê "ampliar o investimento na formação de doutores de modo a atingir a proporção de 4 (quatro) doutores por 1.000 (mil) habitantes" (BRASIL, 2014). Observa-se que a estratégia estipula uma proporção de doutores por habitantes a ser alcançado no período de vigência do PNE, vinculando esse crescimento ao aumento de investimentos para tal finalidade. Dessa forma, a relação entre financiamento e recursos para a pós-graduação e o aumento do número de doutores é enunciada diretamente na própria estratégia da meta 14, o que a torna adequada para a investigação proposta.

Apesar de a meta 14 possuir quinze estratégias elencadas com objetivos e focos diversos visando à expansão, qualificação e interiorização da pós-graduação, este estudo se debruçará apenas ao texto da meta em si e às duas estratégias já apresentadas, a 14.1 e a 14.12, visto que, para que a meta seja alcançada, são necessários recursos e investimentos, conforme previsto pela estratégia 14.1. Complementarmente, a estratégia 14.12 também exige investimentos e apresenta um número objetivo a ser alcançado, que tem relação direta com a expansão de titulados doutores prevista na meta.

Vale mencionar que existem outros documentos centrais que regem e devem servir como parâmetro para o desenvolvimento e expansão da pós-graduação no Brasil, como é o caso do Plano Nacional de Pós-Graduação para o decênio 2010-2020. Conforme sintetizam Kato e Ferreira (2016, p. 684):

\begin{abstract}
Oficialmente, o Plano Nacional de Pós-Graduação (PNPG) 2011-2020 cumpre o objetivo de definir novas diretrizes, estratégias e metas com vistas ao desenvolvimento da pósgraduação e pesquisa no Brasil para o próximo decênio. Alguns eixos são destacados como centrais no âmbito deste documento: a expansão do Sistema Nacional de PósGraduação; a criação de uma agenda nacional de pesquisas; o papel de indução da CAPES e do CNPq; o aperfeiçoamento da avaliação; o apoio aos demais níveis de ensino e a formação de recursos humanos para empresas.
\end{abstract}

O trabalho destas autoras, assim como o de Azevedo, Oliveira e Catani (2016), analisa a pós-graduação e seus documentos norteadores, sobretudo o PNPG, a partir de uma perspectiva crítica relacionada à captura da ciência e do conhecimento pelo capital e sua inserção na lógica capitalista. Entretanto, apesar de abordarem o PNE em seus trabalhos, a 
A Expansão e o Financiamento da Pós-Graduação no Brasil e a Meta 14 do Plano Nacional de Educação

análise e pesquisa dos autores não estão centradas em uma avaliação mais objetiva da meta 14, e apesar de discutirem a questão do financiamento da pós-graduação, não o fazem de maneira específica em relação ao cumprimento da meta e de suas estratégias.

Diante da ausência de estudos com este foco na literatura atual, esta pesquisa se coloca com os objetivos já anunciados, como uma tentativa de investigar as perspectivas de cumprimento do $\mathrm{PNE}$, em relação à meta 14 e às estratégias selecionadas, a partir da ótica do financiamento público para o desenvolvimento da pós-graduação. Como já foi mencionado, o foco da análise recai sobre as duas principais agências federais de fomento da pósgraduação, a CAPES e o CNPq, e a oferta de bolsas de estudos para estudantes de pósgraduação

A CAPES - Coordenação de Aperfeiçoamento de Pessoal de Nível Superior é uma autarquia vinculada ao Ministério da Educação que, segundo o site da própria instituição, "desempenha papel fundamental na expansão e consolidação da pós-graduação stricto sensu (mestrado e doutorado) em todos os estados da Federação" (CAPES, 2018).

De forma específica, a autarquia atua diretamente em:

[...] avaliação da pós-graduação stricto sensu; acesso e divulgação da produção científica; investimentos na formação de recursos de alto nível no país e exterior; promoção da cooperação científica internacional; indução e fomento da formação inicial e continuada de professores para a educação básica nos formatos presencial e a distância (CAPES, 2018).

Além disso, ela é responsável por grande parte das bolsas de estudos, no País e no exterior, financiadas com recursos públicos e voltadas para estudantes de pós-graduação. $O$ Conselho Nacional de Desenvolvimento Científico e Tecnológico (CNPq), por sua vez, conforme apresentado no site da instituição, é uma "agência do Ministério da Ciência, Tecnologia, Inovações e Comunicações (MCTIC), tem como principais atribuições fomentar a pesquisa científica e tecnológica e incentivar a formação de pesquisadores brasileiros" (CNPq, 2018). A instituição também é uma das maiores responsáveis pela oferta de bolsas de estudos para estudantes de pós-graduação.

Cabe ressaltar que as atribuições e programas das duas instituições vão além da oferta de bolsas, destinando recursos a finalidades diversas, como o desenvolvimento de pesquisas científicas e acadêmicas, recursos materiais, laboratórios, entre outros. No caso da CAPES, cabe ainda frisar que, a partir de 2007, a instituição passou a ser responsável por programas de formação dos profissionais da educação básica. Além disso, a oferta de bolsas das duas instituições não se limita à pós-graduação stricto sensu, visto que existem também programas de bolsa voltados para graduação, pós-doutorado, entre outros.

\section{II - O Financiamento da Pós-Graduação, A Oferta de Bolsas e o Cumprimento da Meta 14}

Nesta seção serão analisados os dados referentes à pós-graduação no Brasil relacionados ao cumprimento da meta 14 do PNE e das duas estratégias selecionadas, a partir do financiamento desse nível de ensino, com foco na oferta de bolsas para os estudantes. Os dados foram coletados nas plataformas GEOCAPES, Painel de Investimentos CNPq e Siga Brasil; e nos sites da CAPES, CNPq e MCTIC. 
A Expansão e o Financiamento da Pós-Graduação no Brasil e a Meta 14 do Plano Nacional de Educação

De acordo com os dados do GEOCAPES, em 2016 o Brasil contava com um total de 266.818 estudantes matriculados em cursos de pós-graduação stricto sensu. Desse total, 126.436 eram estudantes do mestrado acadêmico, 32.742 do mestrado profissional e 107.640 do doutorado acadêmico. Esse número representa um crescimento de aproximadamente $130 \%$ em relação ao número total de matriculados no ano de 2004 , que era de 116.260 estudantes.

Crescimento semelhante verifica-se em relação ao número de discentes titulados, ao final do ano, em pós-graduação stricto sensu, conforme se observa no gráfico abaixo:

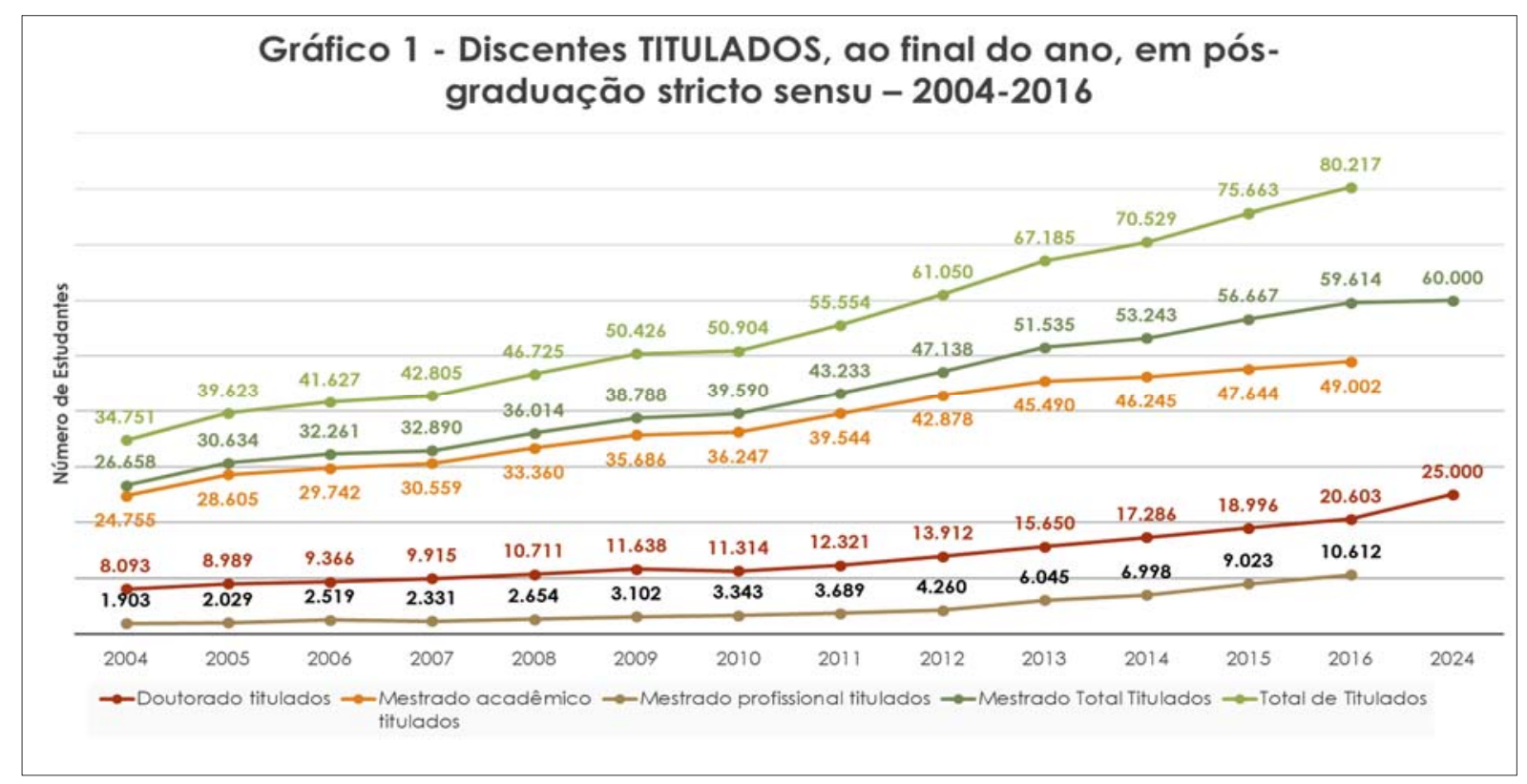

Fonte: Elaboração do autor com base em GEOCAPES.

Como é possível observar, o número total de titulados aumentou $131 \%$ no período analisado. Em relação ao número de titulados/ano em mestrado, o crescimento no período foi de $124 \%$, de forma que o objetivo previsto na meta 14 está próximo de ser alcançado, de maneira que um crescimento de apenas $0,6 \%$ seja necessário. Entretanto, esse número não é cumulativo, ou seja, é necessário que essa razão seja mantida, senão ampliada nos próximos anos até 2024 , ainda que a meta não especifique o prazo de cumprimento. Já em relação ao número de titulados/ano em doutorado, o crescimento foi de $154 \%$ no período, porém ainda são necessários avanços para que se alcance o número de 25 mil titulados/ano previstos na meta. Apesar de apresentar uma maior taxa de crescimento nos últimos anos se comparado com titulados/ano em mestrado, ainda é necessário manter tais taxas para que se possa chegar ao crescimento de $21,3 \%$ necessário para o cumprimento da meta, em relação ao patamar de 2016.

No período de 2004-2016, tal como o número de titulados/ano e matriculados na pósgraduação stricto sensu, o número de bolsistas vinculados à CAPES e ao CNPq também aumentou, conforme verifica-se no gráfico abaixo: 


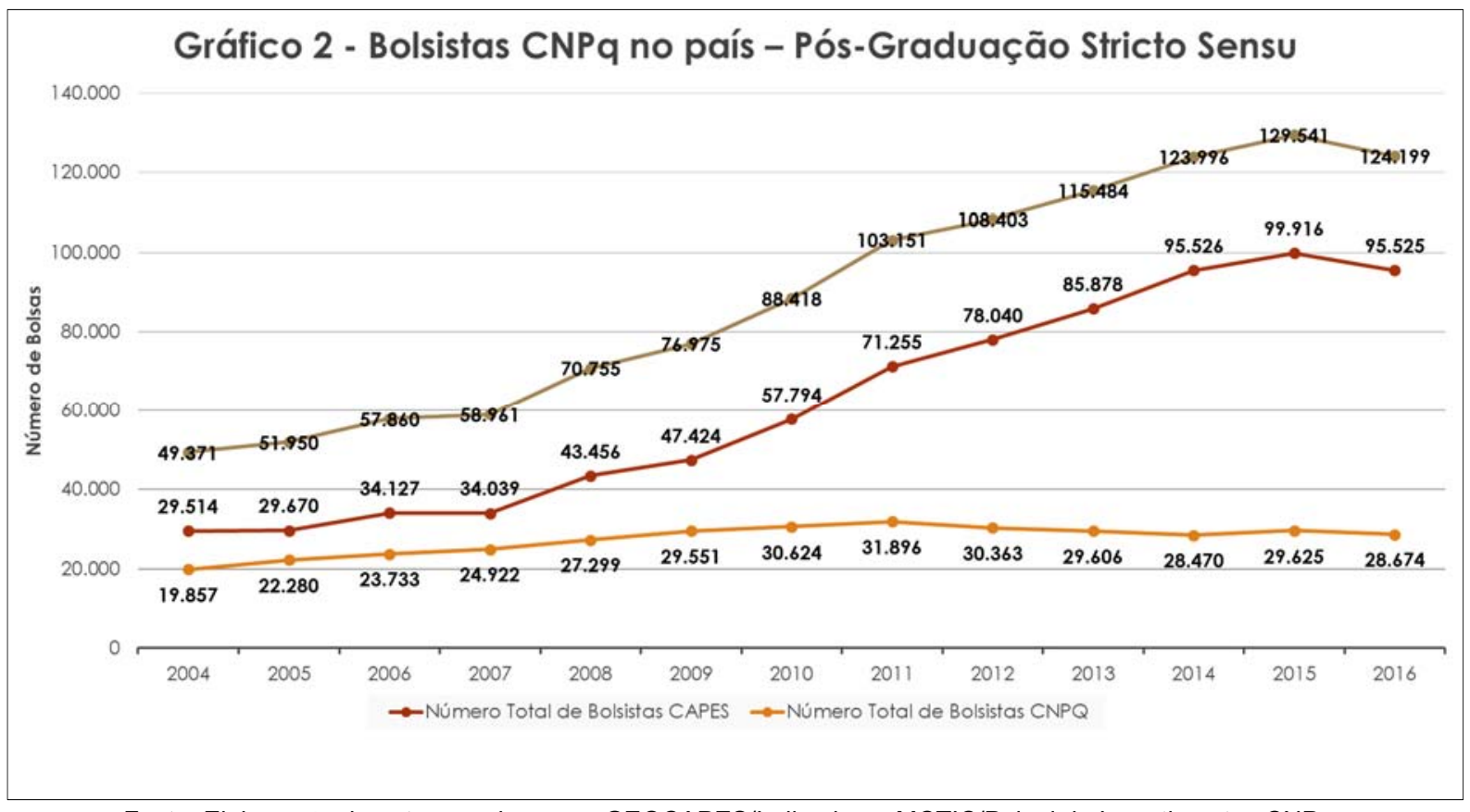

Fonte: Elaboração do autor com base em GEOCAPES/Indicadores MCTIC/Painel de Investimentos CNPq.

Os dados acima se referem apenas ao número de bolsistas de pós-graduação stricto sensu, ou seja, mestrado acadêmico e profissional e doutorado, no País e no exterior. O crescimento de $152 \%$ no número de bolsistas é resultado sobretudo do papel da CAPES, responsável por um crescimento de $224 \%$ de bolsistas vinculados à instituição. O CNPq também apresentou crescimento de bolsistas, porém bem mais reduzido, de $44 \%$ no período.

Chama a atenção que as duas agências apresentaram redução do número de bolsistas no último ano, o que levou a uma diminuição no total de bolsistas. Já o CNPq, desde 2012, apresenta decrescimento do número de bolsistas. Esses dados podem representar um impacto negativo relevante, visto que há uma redução de $4,1 \%$ no número total de bolsistas de 2015 para 2016, o que pode comprometer seriamente a continuidade das taxas de crescimento de matriculados e titulados e, consequentemente, ampliar a distância para o alcance da meta prevista. No caso de bolsistas no exterior, a redução no último ano foi de $32 \%$, considerando as duas agências, o que reflete um desmonte das políticas de internacionalização do conhecimento, da pesquisa e da pós-graduação no Brasil.

Em relação aos recursos das duas agências para financiar bolsas para estudantes de pós-graduação stricto sensu, verificou-se uma elevação dos recursos destinados para esse fim. De acordo com os dados da Tabela de Evolução Orçamentária da CAPES ${ }^{1}$, os valores executados em recursos para bolsas passaram de $R \$ 945.000 .000$, em 2004, para $\mathrm{R} \$ 2.567 .000 .000$, em 2016, em valores reais corrigidos pelo IPCA 2016, representando um aumento de $172 \%$. Já o CNPq apresentou um tímido aumento de $10 \%$ de recursos para bolsas, passando de $\mathrm{R} \$ 438.000 .000$ para $\mathrm{R} \$ 482.000 .000$, de 2004 para 2016. O gráfico abaixo ilustra o crescimento de recursos no período 2004-2016²:

1 Disponível em: <http://www.capes.gov.br/images/stories/download/diversos/02052017-ORCAMENTO-PORPPA-2004-2019.pdf>.

2 Os recursos da CAPES referem-se aos valores totais de recursos para bolsas sem distinção por modalidade, enquanto que os recursos do CNPq estão discriminados em bolsas de doutorado, doutorado no exterior, 
A Expansão e o Financiamento da Pós-Graduação no Brasil e a Meta 14 do Plano Nacional de Educação

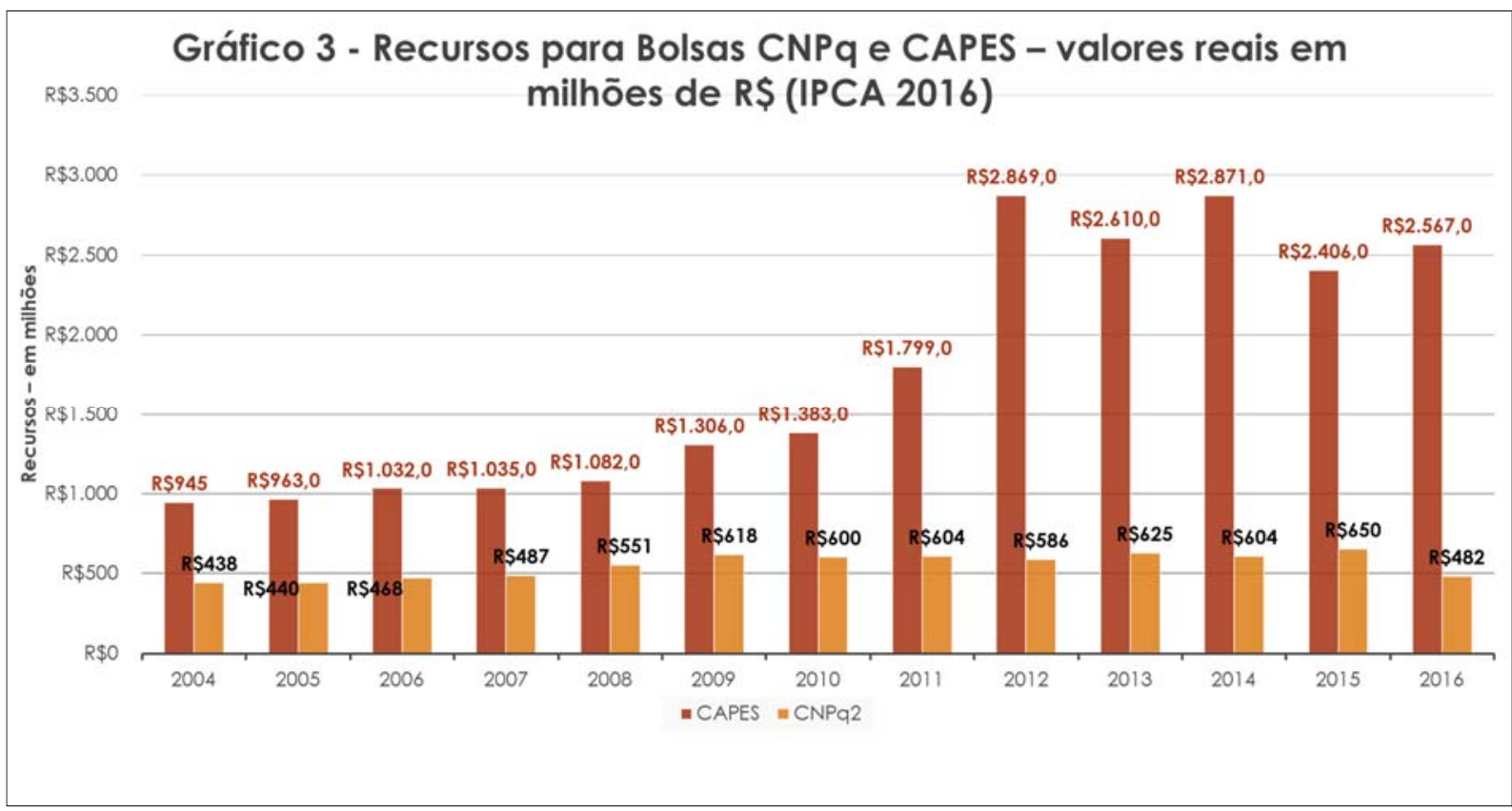

Fonte: Elaboração do autor com base em CAPES - Tabela de Evolução Orçamentária/Painel de Investimentos CNPq.

Somados os recursos das duas agências para bolsas, houve aumento de $120 \%$ no período analisado, sendo a CAPES a grande responsável por parcela desse crescimento e pelo montante de recursos. Entretanto, assim como o número de bolsistas, os recursos públicos para bolsas também vêm apresentando reduções preocupantes. Apenas no último ano, o CNPq apresentou redução de 25,9\% nos recursos e a CAPES apresentou redução de 16,6\% em recursos para bolsas de 2014 para 2015. Essas reduções implicam diminuições significativas no total de recursos para bolsas na ordem de $12,2 \%$ dos recursos nos últimos dois anos analisados.

Quanto ao orçamento total das duas agências, verificou-se um aumento exponencial de recursos da CAPES, enquanto o CNPq apresentou uma pequena redução dos recursos no período analisado. A partir dos dados disponíveis no site SIGA BRASIL, referentes a valores reais pagos e corrigidos pelo IPCA de 2016, verifica-se um crescimento de $414 \%$ no orçamento da CAPES, passando de $\mathrm{R} \$ 983.000 .000$ para $\mathrm{R} \$ 5.059 .000 .000$, de 2004 para 2016, enquanto o CNPq, no mesmo período, teve seu orçamento reduzido de $\mathrm{R} \$ 1.394 .000 .000$ para $\mathrm{R} \$ 1.292 .000 .000$, uma diminuição de $7 \%$. Em relação ao total de recursos das duas agências, houve um aumento de $167 \%$ no período.

No período analisado, a CAPES apresentou um aumento exponencial de seu orçamento, impulsionado também pelas novas atribuições em relação à educação básica, a partir de 2007, pelo programa Ciência Sem Fronteiras a partir de 2012, e também pelo elevado número de bolsistas de pós-graduação. É importante salientar que, em 2004, o orçamento do CNPq era maior que o da CAPES, cenário que se inverteu a partir de 2008, passando a representação da CAPES no total de recursos de 41\%, em 2004, para 80\%, em 2016.

doutorado sanduíche, doutorado sanduíche no exterior e mestrado. Outra observação refere-se ao ano de 2012, em que o orçamento do Programa Ciência Sem Fronteiras está contabilizado do cômputo geral das bolsas, entretanto nos anos subsequentes foi contabilizado em uma rubrica à parte. 
A Expansão e o Financiamento da Pós-Graduação no Brasil e a Meta 14 do Plano Nacional de Educação

Entretanto, assim como os recursos destinados às bolsas, o orçamento de ambas as instituições tem sofrido graves reduções. Em 2016, o orçamento da CAPES encolheu 37,7\%, ao mesmo tempo que o do CNPq diminuiu 19,5\%, já tendo registrado redução de $27,2 \% \mathrm{em}$ 2015. No total, o orçamento das duas agências sofreu redução de $35 \%$ em 2016. Como é possível perceber pelos dados, a diminuição dos orçamentos das duas agências de fomento federais contraria o cumprimento da estratégia 14.1 do PNE, de forma que, ao invés de expandir o financiamento da pós-graduação por meio delas, o governo passa sistematicamente a promover cortes profundos de recursos, reflexo de uma política econômica de orientação neoliberal e de desmantelamento do Estado.

O corte orçamentário das agências produz efeitos diretos na redução dos recursos para bolsas e, consequentemente, no número de bolsas ofertadas, o que, por sua vez, compromete o aumento do número de titulados/ano. Ao comparar as variações de crescimento de bolsistas, recursos para bolsas e quantidade de titulados/matriculados, é possível verificar as relações entre esses elementos, de forma que se verifica coincidência entre os períodos de maior e menor crescimento de cada aspecto. Isso ocorre, sobretudo, a partir de 2015, quando as reduções orçamentárias e de bolsas também refletem uma diminuição do crescimento de matriculados e titulados/ano em pós-graduação stricto sensu.

O quadro abaixo sintetiza as variações dos aspectos analisados:

\begin{tabular}{|c|c|c|c|c|c|c|c|c|}
\hline \multicolumn{9}{|c|}{$\begin{array}{l}\text { QUADRO 1- DADOS COMPARATIVOS 2004-2016 - } \\
\text { Valores reais em milhöes de RS (IPCA 2016) }\end{array}$} \\
\hline Ano & \begin{tabular}{l|} 
Orçamento \\
CAPES
\end{tabular} & \begin{tabular}{|l|} 
Recursos \\
Capes em \\
Bolsas
\end{tabular} & $\begin{array}{l}\text { Orçamento } \\
\text { CNPq }\end{array}$ & \begin{tabular}{|l|} 
Recursos \\
CNPq em \\
Bolsas
\end{tabular} & $\begin{array}{l}\text { Matriculados } \\
\text { Pós- } \\
\text { Graduação }\end{array}$ & \begin{tabular}{|l|} 
Titulados \\
Pós- \\
Graduação \\
\end{tabular} & $\begin{array}{l}\text { Bolsistas } \\
\text { CAPES }\end{array}$ & $\begin{array}{l}\text { Bolsistas } \\
\text { CNPq }\end{array}$ \\
\hline 2004 & R\$983 & R\$945 & R\$1.394 & $\mathrm{R} \$ 438$ & 116.260 & 34.751 & 29.514 & 19.857 \\
\hline 2016 & $\mathrm{R} \$ 5.059$ & $\mathrm{R} \$ 2.567$ & $\mathrm{R} \$ 1.292$ & R\$482 & 266.818 & 80.217 & 95.525 & 28.674 \\
\hline$\%$ & $414 \%$ & $172 \%$ & $-7 \%$ & $10 \%$ & $130 \%$ & $131 \%$ & $224 \%$ & $44 \%$ \\
\hline
\end{tabular}

Fonte: Elaboração do autor com base em CAPES - Tabela de Evolução Orçamentária/Painel de Investimentos CNPq/GEOCAPES/SIGA BRASIL/INDICADORES MCTIC.

No período 2004-2016, há um crescimento significativo do número de estudantes matriculados/titulados na pós-graduação stricto sensu, que é acompanhado por um crescimento do número de bolsas ainda maior e de recursos destinados ao pagamento dessas bolsas pelas agências de fomento. Destas, a que mais se destacou no crescimento orçamentário, como também na quantidade de bolsistas e de recursos para bolsas, foi a CAPES, com um aumento de bolsistas de $224 \%$ no período. Nota-se também uma redução do orçamento do CNPq e um tímido aumento dos recursos para bolsas no período analisado, apesar de ter expandido seu número de bolsistas.

Quanto à estratégia 14.12, que estipula expandir investimentos de modo a alcançar a proporção de 4 doutores por 1.000 habitantes, os resultados mostram dados alarmantes, que inclusive apontam não apenas o não cumprimento da estratégia, mas para a dissonância entre 
A Expansão e o Financiamento da Pós-Graduação no Brasil e a Meta 14 do Plano Nacional de Educação

a estratégia e a meta. Conforme apontam dados do CNPq ${ }^{3}$ e do IBGE, em 2004, havia no Brasil 47.971 doutores em uma população de 181 milhões de habitantes, estabelecendo uma proporção de 0,26 doutor por mil habitantes. Esse número em 2014 ampliou-se timidamente para 0,69 doutor por mil habitantes, numa população de 202 milhões de habitantes, em que existiam apenas 140.272 doutores.

Para se alcançar a proporção de quatro doutores por mil habitantes, como prevê a estratégia 14.12, e considerando a estimativa populacional do IBGE para 2024 de 217.193.000 de habitantes, seriam necessários 868.772 doutores no País. Levando em conta que de 2014 para 2016 houve uma redução de $26 \%$ nos recursos para bolsas do CNPq para doutorado, doutorado no exterior, doutorado sanduíche e doutorado sanduíche no exterior, verifica-se que o Brasil está longe de ampliar investimento na formação de doutores, como prevê a estratégia, e mais longe ainda de alcançar o número de doutores necessários para tal.

Além disso, considerando-se o número de doutores existentes em 2014 e somando-se os titulados em 2015 (18.996 titulados) e 2016 (20.063 titulados), e se a partir de então adicionarmos 25 mil titulados por ano, como prevê a meta 14, num cenário hipotético em que não haveria a diminuição de doutores já existentes, resultaria, no ano de 2024 , em cerca de 380 mil doutores no País.

Considerando o cenário real, no qual o número de recursos e de bolsas vêm diminuindo, e que o ritmo de crescimento de titulados e matriculados vêm desacelerando, é possível visualizar que em 2024 o Brasil estará muito distante do cumprimento da estratégia 14.12. Por fim, percebe-se uma incompatibilidade entre a própria meta, que estipula titulação anual de 25 mil doutores, e a estratégia 14.12, que demandaria um número muito maior que o previsto na meta para que se alcance a proporção pretendida de quatro doutores por mil habitantes.

\section{Considerações Finais}

A partir das análises realizadas, conclui-se que o número de matriculados e titulados na pós-graduação stricto sensu cresceu ao longo dos últimos anos. A partir de 2004, é possível verificar que tal crescimento foi acompanhado pelo aumento do número de bolsistas financiados pelas duas principais agências federais de fomento, CAPES e CNPq. Paralelamente, também houve expansão de recursos dessas agências para o financiamento de bolsas na pós-graduação, assim como do orçamento total das duas agências.

Entretanto, nos últimos anos, sobretudo a partir de 2015, é possível verificar uma redução na quantidade de bolsistas, nos recursos destinados às bolsas (com exceção da CAPES), e nos orçamentos das duas principais agências de fomento. Tais dados convergem na queda na taxa de crescimento do número de matriculados e titulados/ano na pósgraduação stricto sensu, de forma que, caso mantidos os cortes orçamentários, poderá significar redução a curto prazo.

Com efeito, quanto à meta 14 , apesar de já estar próximo de seu cumprimento em relação à titulação de mestres, ainda é necessário crescer em $21 \%$ o número de titulados

3 Tabela 1.5.8 CNPq - Número de doutores por habitantes segundo região e unidade da federação - 2000-2014. 
A Expansão e o Financiamento da Pós-Graduação no Brasil e a Meta 14 do Plano Nacional de Educação

doutores. Para isso, é necessário elevar, ou no mínimo manter, os recursos destinados às bolsas e o número de bolsistas, e consequentemente o orçamento das agências de fomento.

Em relação ao cumprimento da Estratégia 14.1, verificou-se que, apesar de uma expansão de seus orçamentos, nos últimos anos os recursos orçamentários da CAPES e do CNPq vêm sofrendo duros cortes, que se refletem diretamente no número de bolsas, na qualidade da pós-graduação e no cumprimento da meta 14 . Somente em relação ao último ano, 2016, a redução total foi de cerca de $35 \%$ para a CAPES e $20 \%$ para o CNPq, que já vinha acumulando reduções. Ou seja, caminha-se no sentido oposto daquele que a meta orienta.

Quanto à Estratégia 14.12, verificou-se que seu cumprimento beira o impossível ao se considerar a atual trajetória quantitativa de doutores, titulados e recursos destinados à formação de doutores. Até mesmo se cumprido o texto da meta 14, o cumprimento dessa estratégia permanece distante.

Conclui-se que o financiamento da pós-graduação possui um papel fundamental no cumprimento da meta proposta no Plano Nacional de Educação, e que, por sua vez, as bolsas destinadas aos estudantes são um elemento central na expansão e desenvolvimento desse nível de ensino, sobretudo no que se refere à titulação dos estudantes. Com isso, serão necessários recursos massivos na pós-graduação, principalmente, nas agências de fomento e no orçamento destinado às instituições de educação superior públicas, para que se possa recuperar o patamar de desenvolvimento anterior e tornar a expandir a educação superior e a pós-graduação no Brasil.

Entretanto, a necessidade contrasta com a realidade: o projeto econômico em curso, de orientação neoliberal e privatista, e estabelecido a partir do golpe parlamentar consolidado no impeachment da presidenta Dilma Rousseff, vem executando o desmonte do Estado brasileiro e tem as instituições de educação superior federais como uma de suas principais vítimas. A aprovação da Emenda Constitucional $n^{\circ}$ 95/2016 impôs um teto de crescimento aos gastos públicos, incluído os gastos educacionais, o que compromete gravemente o cumprimento do PNE (AMARAL, 2017). Paralelamente, o discurso de acabar com a gratuidade da educação superior pública vem cada vez mais tomando fôlego, no caso da pós-graduação a PEC $n^{\circ}$ 395/2014, que autorizava as universidades públicas a cobrar por cursos de extensão e pósgraduação lato sensu, foi uma dessas tentativas, questão bem elucidada por Kato e Ferreira (2016).

Dessa forma, o cenário para a pós-graduação é crítico, bem como para toda a educação superior, e os resultados desta pesquisa convergem com Chaves e Amaral (2014) ao avaliarem a política de financiamento da educação superior:

Como pode ser observado, as três metas propostas para a educação superior destacam a necessidade da expansão desse nível de ensino, no entanto, não fica claro se as estratégias definidas para atendimento das metas, no que se refere ao financiamento, serão suficientes uma vez que não são apresentados dados que indiquem isso (CHAVES; AMARAL, 2014, p. 51).

Portanto, apesar de ter-se avançado consideravelmente a partir de 2004, seja com relação a recursos, bolsas ou número de estudantes matriculados e titulados, são necessários mais recursos públicos, de forma a garantir a expansão e o desenvolvimento da pósgraduação, contando com criação de novas vagas, mais investimentos, mais estruturas e uma 
A Expansão e o Financiamento da Pós-Graduação no Brasil e a Meta 14 do Plano Nacional de Educação

maior oferta de bolsas para os estudantes. Apenas com essas mudanças será possível alcançar o proposto no Plano Nacional de Educação quanto à pós-graduação.

\section{Referências}

AMARAL, Nelson Cardoso. Com a PEC 241/55 (EC 95) haverá prioridade para cumprir as metas do PNE (2014-2024)?. Revista Brasileira de Educação, Rio de Janeiro, v. 22, n. 71, e227145, 2017. Disponível em: <http://www.scielo.br/scielo.php?script=sci_arttext \&pid=S141324782017000400200\&lng=en\&nrm=iso>. Acesso em: 10 jan. 2018.

AZEVEDO, Mário Luiz Neves de; OLIVEIRA, João Ferreira de; CATANI, Afrânio Mendes. O Sistema Nacional de Pós-graduação (SNPG) e o Plano Nacional de Educação (PNE 20142024): regulação, avaliação e financiamento. Revista Brasileira de Política e Administração da Educação, Goiânia, ANPAE, v. 32, n. 3, p. 783-803, dez. 2016. Disponível em: <http://seer.ufrgs.br/index.php/rbpae/article/view/68576>. Acesso em: 10 jan. 2018.

BRASIL. Constituição da República Federativa do Brasil, de 5 de outubro de 1988. Diário Oficial [da] República Federativa do Brasil, Brasília, DF, 5 out. 1988. Disponível em: $<$ http://www2.camara.leg.br/atividadelegislativa/legislacao/Constituicoes_Brasileiras/constitui cao1988.html>. Acesso em: 10 out. 2018.

BRASIL. Lei 13.005, de 24 de junho de 2014. Aprova o Plano Nacional de Educação - PNE e dá outras providências. Diário Oficial da União, Brasília, 2014. Disponível em: <http://www.planalto.gov.br/ccivil_03/_ato2011-2014/2014/lei//13005.htm>. Acesso em: 10 out. 2018.

CAPES. História e Missão. Brasília, 2018. Disponível em: <http://www.capes.gov.br/historiae-missao>. Acesso em: 10 out. 2018.

CAPES. Tabela de Evolução Orçamentária. Brasília, 2018. Disponível em: <http://www.capes.gov.br/orcamento-evolucao-em-reais>. Acesso em: 10 out. 2018.

CHAVES, Vera Lúcia Jacob; AMARAL, Nelson Cardoso. Política de Financiamento da Educação Superior - Análise dos Planos Nacionais de Educação Pós-Constituição/1988. Revista Eletrônica de Educação, São Carlos, v. 8, p. 43-55, 2014.

CNPq. Estatísticas e Indicadores. Brasília, 2018. Disponível em: <http://www.cnpq.br/web/guest/apresentacao3/>. Acesso em: 10 out. 2018.

CNPq. O CNPq. Brasília, 2018. Disponível em: <http://cnpq.br/apresentacao_institucional/>. Acesso em: 10 out. 2018.

DOURADO, Luiz Fernandes. Plano Nacional de Educação: política de Estado para a educação brasileira. Brasília: Inep, 2016.

GEOCAPES. Brasília, 2018. Disponível em: <https://geocapes.capes.gov.br/geocapes/>. Acesso em: 10 out. 2018.

INDICADORES MCTIC. Brasília, 2018. Disponível em: <https://www.mctic.gov.br/mctic/o pencms/indicadores/indicadores_cti.html>. Acesso em: 10 out. 2018.

KATO, Fabíola Bouth Grello; FERREIRA, Luciana Rodrigues. A política de expansão e financiamento da pós-graduação: as diretrizes do PNPG (2011-2020) e PNE (2014-2024). 
A Expansão e o Financiamento da Pós-Graduação no Brasil e a Meta 14 do Plano Nacional de Educação

Revista Brasileira de Política e Administração da Educação, Goiânia, ANPAE, v. 32, n. 3, p. 677-697, dez. 2016. ISSN 2447-4193.

PAINEL DE INVESTIMENTOS CNPq. Brasília, 2018. Disponível em: <http://estatico.cnpq.br/painel-investimentos>. Acesso em: 10 out. 2018.

SIGA BRASIL. Brasília, 2018. Disponível em: <https://www12.senado.leg.br/orcam ento/sigabrasil>. Acesso em: 10 out. 2018.

Caio Eduardo Jardim é mestre em Educação, na linha Política e Gestão da Educação, pela Universidade de Brasília (UnB), pós-graduado em Supervisão e Orientação Educacional e bacharel em Ciência Política (UnB). Possui atuação nas áreas de Ciência Política, Gestão Pública e Políticas Públicas, Participação Social e Democracia, Educação, Política e Gestão da Educação, Financiamento da Educação, e Pedagogia.

ORCID: http://orcid.org/0000-0001-6449-8360

E-mail: caiojardim47@gmail.com 


\section{Editores do volume 10}

Márcia Aparecida Jacomini - Universidade Federal de São Paulo, Brasil

José Marcelino de Rezende Pinto - Universidade de São Paulo, Brasil

\section{Comitê Editorial}

Nalú Farenzena - Universidade Federal do Rio Grande do Sul, Brasil

Juca Gil - Universidade Federal do Rio Grande do Sul, Brasil

Theresa Adrião - Universidade Estadual de Campinas, Brasil

Ângelo Ricardo de Souza - Universidade Federal do Paraná, Brasil

\section{Conselho Editorial}

\section{Alejandro Morduchowicz}

Universidad Pedagógica, Provincia de Buenos Aires, Argentina

Andréa Barbosa Gouveia

Universidade Federal do Paraná, Brasil

Fernanda Saforcada

Universidade de Buenos Aires, Argentina

Jacques Velloso

Universidade de Brasília, Brasil

João Monlevade

Senado Federal, Brasil

Jorge Abrahão de Castro

Instituto de Pesquisa Econômica Aplicada / IPEA, Brasil

Lisete Regina Gomes Arelaro

Universidade de São Paulo, Brasil

Luis Carlos Sales

Universidade Federal do Piauí, Brasil

Luiz de Sousa Junior

Universidade Federal da Paraíba, Brasil

Luiz Fernandes Dourado

Universidade Federal de Goiás, Brasil

Magna França

Universidade Federal do Rio Grande do Norte, Brasil

Marcos Edgar Bassi

Universidade Federal de Santa Catarina, Brasil

Maria Angélica Pedra Minhoto

Universidade Federal de São Paulo, Brasil

Maria Beatriz Luce

Universidade Federal do Rio Grande do Sul, Brasil

Maria Dilnéia Espíndola Fernandes

Universidade Federal de Mato Grosso do Sul, Brasil

Nelson Cardoso do Amaral

Universidade Federal de Goiás, Brasil

Nicholas Davies

Universidade Federal Fluminense, Brasil

Robert E. Verhine

Universidade Federal da Bahia, Brasil

Romualdo Portela de Oliveira Universidade de São Paulo, Brasil

Rosana Gemaque Rolim

Universidade Federal do Pará, Brasil

Rubens Barbosa de Camargo

Universidade de São Paulo, Brasil

Theresa Adrião

Universidade Estadual de Campinas, Brasil

Tristan McCowan

University of London, Reino Unido

Vera Jacob

Universidade Federal do Pará, Brasil

Vera Peroni

Universidade Federal do Rio Grande do Sul, Brasil

Vitor Henrique Paro

Universidade de São Paulo, Brasil

\section{Equipe editorial}

Apoio ao Comitê Editorial: Caio Cabral da Silva

Diagramação, Revisão de português e normalização: Edson Leonel de Oliveira

Revisão de inglês: Ananyr Porto Fajardo

Fineduca - Revista de Financiamento da Educação

Associação Nacional de Pesquisa em

Financiamento da Educação

e-mail: revista.fineduca@gmail.com | site: http://seer.ufrgs.br/fineduca 